\title{
Shear rupture - two case studies from a deep mine
}

\author{
RP Bewick Golder Associates Ltd., Canada \\ PK Kaiser Laurentian University, Canada \\ WF Bawden University of Toronto, Canada
}

\begin{abstract}
When a fault-slip event mechanism is determined, it is easy to assume that there must be a fault present to generate the event. A pre-existing fault is not needed to create a fault-slip event. Fault rupture (the failure process in brittle rocks which occurs under confined conditions) also generates a fault-slip focal mechanism. Fault ruptures will commonly occur far from mining, in abutments, wide pillars, and sills. First the rupture process is overviewed. Then two mining fault rupture case examples are summarised to show the fault rupture process, final rupture geometry, and energy release potential observed in the field conform to theoretical understanding. In this article it is shown that the fault rupture process and energy release depends on the boundary condition (system stiffness) surrounding the failure process. While seemingly theoretical, the findings have practical significance with respect to rock mass characterisation, microseismic monitoring, rock mass behaviour back analysis, and mining strategy.
\end{abstract}

\section{$1 \quad$ Shear rupture process}

Shear rupture is a failure process which occurs in brittle rocks under confined conditions and is the process which leads to the creation of some faults. In mining, this failure process can occur under a variety of boundary conditions ranging from constant stress to constant stiffness. Depending on the boundary condition surrounding the rupture process, different rupture creation processes and behaviours occur (Bewick et al. 2013a, b, c; Bewick 2013).

Under constant normal stress $\left(\sigma_{n}\right)$ boundary conditions, the shear rupture process, the rupture mechanism, rupture zone geometry, and shear stress versus horizontal displacement response of intact brittle rocks are dependent on the normal stress to uniaxial compressive strength (UCS) ratio ( $\sigma_{n} /$ UCS) (Bewick et al. 2013a, b) as illustrated by Figure 1 and summarised as follows:

- As a brittle rock is loaded, a distributed damage zone is created prior to reaching peak strength.

- At low ratios $\left(\sigma_{n} /\right.$ UCS $\left.<0.17\right)$ (Figure $1(c)$ ), shear rupture occurs in a predominantly tensile splitting mode; a process that occurs at or just after peak shear strength is reached. The load-displacement response is brittle with a large post-peak strength drop and the rupture zone is relatively thin and planar.

- At higher ratios ( $\sigma_{n} /$ UCS $\left.0.17-0.62\right)$, shear rupture occurs progressively in a shear mode. First, an array of en échelon fractures develops followed by linkages of the fracture array leading to a shear rupture surface with a relatively wide damage zone. The load-displacement response is strain-weakening at the lower limit of the range of $\sigma_{n} /$ UCS (Figure $1(b)$ ) to one with no strength drop post-peak strength at high $\sigma_{n} /$ UCS (Figure $1(a)$ ). The rupture zone is relatively wide, discontinuous, and irregular. 
a)

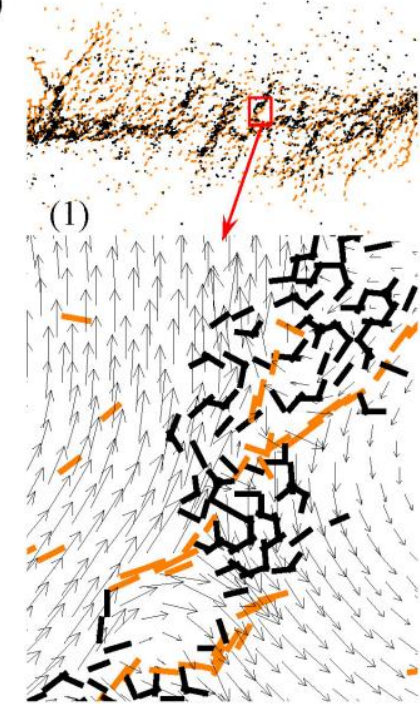

Elastic-plastic stress-strain response

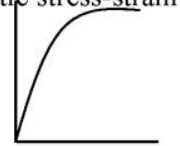

$0.50<\sigma_{\mathrm{n}} / \mathrm{UCS}<1.0$

(Shear rupture: en échelon shear fracture arrays) b)

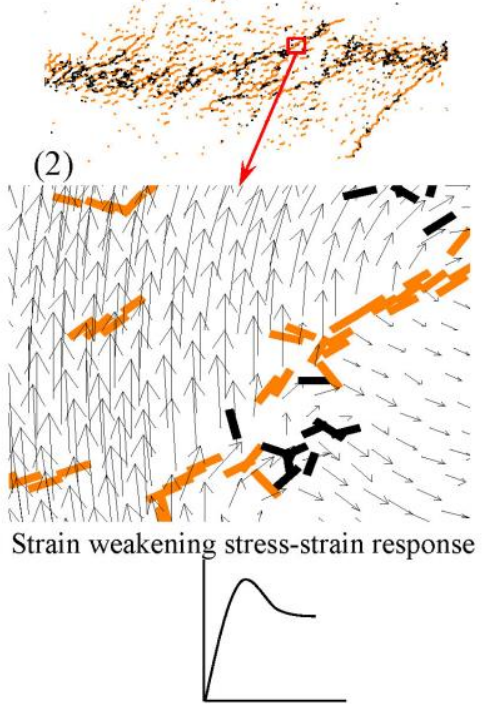

$0.17<\sigma_{\mathrm{n}} / \mathrm{UCS}<0.50$

(Shear rupture: en échelon tensile fracture arrays) c)

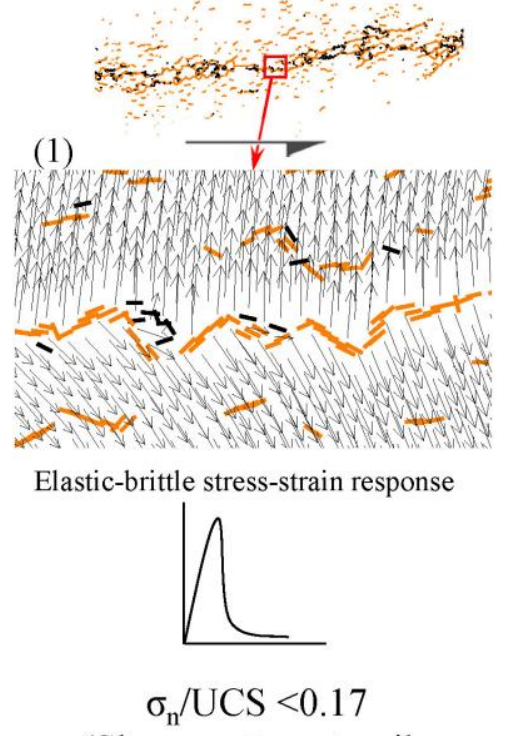

(Shear rupture; tensile splitting mechanism)

Figure 1 Shear rupture process under constant normal stress boundary conditions; (a) high; (b) moderate; and (c) low normal stress to compressive strength ratios

Under constant normal stiffness boundary conditions, the rupture zone creation process is quite different. Opposed to post-peak rupture zone creation and a changing rupture mechanism as shown for the constant normal stress boundary condition above, under constant normal stiffness (Hallbauer et al. 1973; Bewick 2013c) (Figure 2):

- As the stress-path progresses to the rupture envelope, again a distributed damage zone is created (prior to point 1 in Figure 2).

- But once the rupture envelope is reached, a yield point is hit and an en échelon tensile fracture system is generated (points 1 to 2 in Figure 2).

- The stress-path then follows the strength envelope and a rupture zone is created pre-maximum peak strength (opposed to post-peak as outlined above for constant normal stress boundary conditions) (points 2 to 3 in Figure 2).

- While the rupture envelope is followed, shear stress oscillations occur along the shear stress versus horizontal displacement curve. These oscillations are related to rupture zone creation and cohesion loss processes (meaning fracturing) which also creates steps in the cumulative number of fractures curves (not shown in Figure 2).

- At maximum peak strength, the stress-path progresses to a frictional residual strength (points 3 to 4 in Figure 2).

- Under this boundary condition, the post-peak stress drop is always large and brittle (points 3 to 4 in Figure 2). 

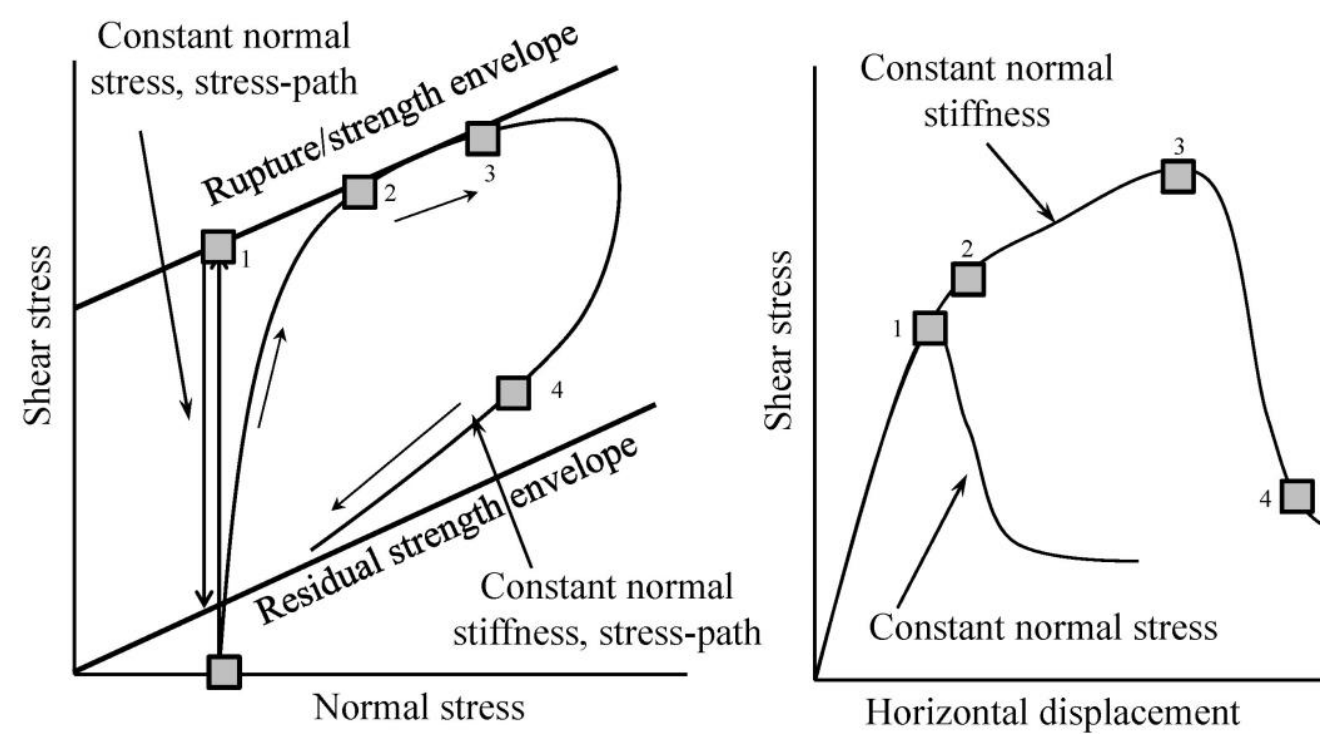

Horizontal displacement
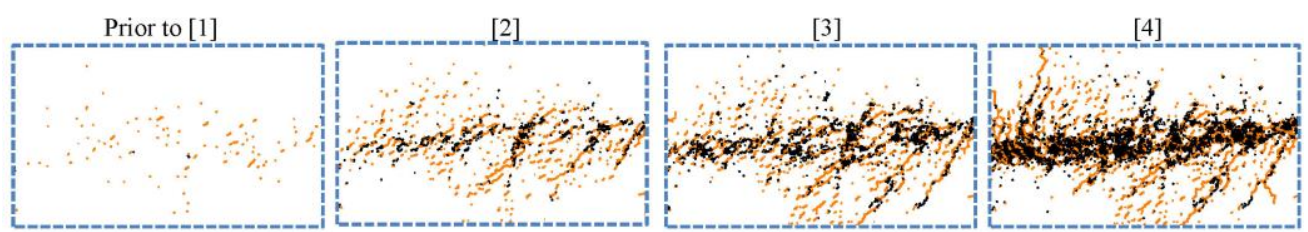

Figure 2 Shear rupture process under constant normal stiffness boundary conditions. Lower rupture images show shear rupture development linked to the shear stress versus normal stress and load-displacement curves above. Also showing constant normal stress stress-paths and load-displacement curves for comparison

\section{$2 \quad$ Evidence of boundary conditions and shear rupture in mines}

The failure process of two mine pillars previously studied by Coulson (2009) are re-interpreted within the framework of boundary condition effects on shear rupture zone creation and behaviour (microseismic and deformation). The first pillar, Case 1, is of trapezoidal shape, is isolated from active mining, and located in the Golden Giant Mine at a depth below surface of approximately $720 \mathrm{~m}$. This pillar fractured by the creation of two pairs of conjugate rupture zones which developed over the period of a few months (Coulson 2009). The rupture process is reflected in microseismic patterns. No large magnitude seismic events or rockbursts were generated during fracturing and rupture, i.e. events were of Nuttli magnitude $\mathrm{Mn}<0$. The second pillar, Case 2, is a footwall sill pillar at the Williams mine located at a depth below surface of approximately $915 \mathrm{~m}$. This pillar fractures by the creation of a single rupture zone over a four year time period (Coulson 2009). The fracturing leading to the rupture of the pillar was associated with microseismicity but several seismic events (magnitude from $M n=0.5-3.5$ ) and a rockburst $(M n=2.7$ ) were also generated by or associated with the rupture process.

Both pillars fail by fracturing processes leading to shear rupture zone creation. They are observed to have different behaviour and fracture process characteristics. The behaviour and rupture process differences are shown to be due to different boundary conditions.

\subsection{Case 1 pillar - Golden Giant Mine}

The Golden Giant pillar (Figure 3) is an isolated pillar with no current active mining surrounding it. It is located near the shaft of the Golden Giant Mine and above mined out stopes of the neighbouring David Bell Mine. The pillar is trapezoidal in shape approximately $53 \mathrm{~m}$ east-west (length), 6-25 m north-south (thickness), and $20 \mathrm{~m}$ in vertical dimension (Figure 3(c)). 


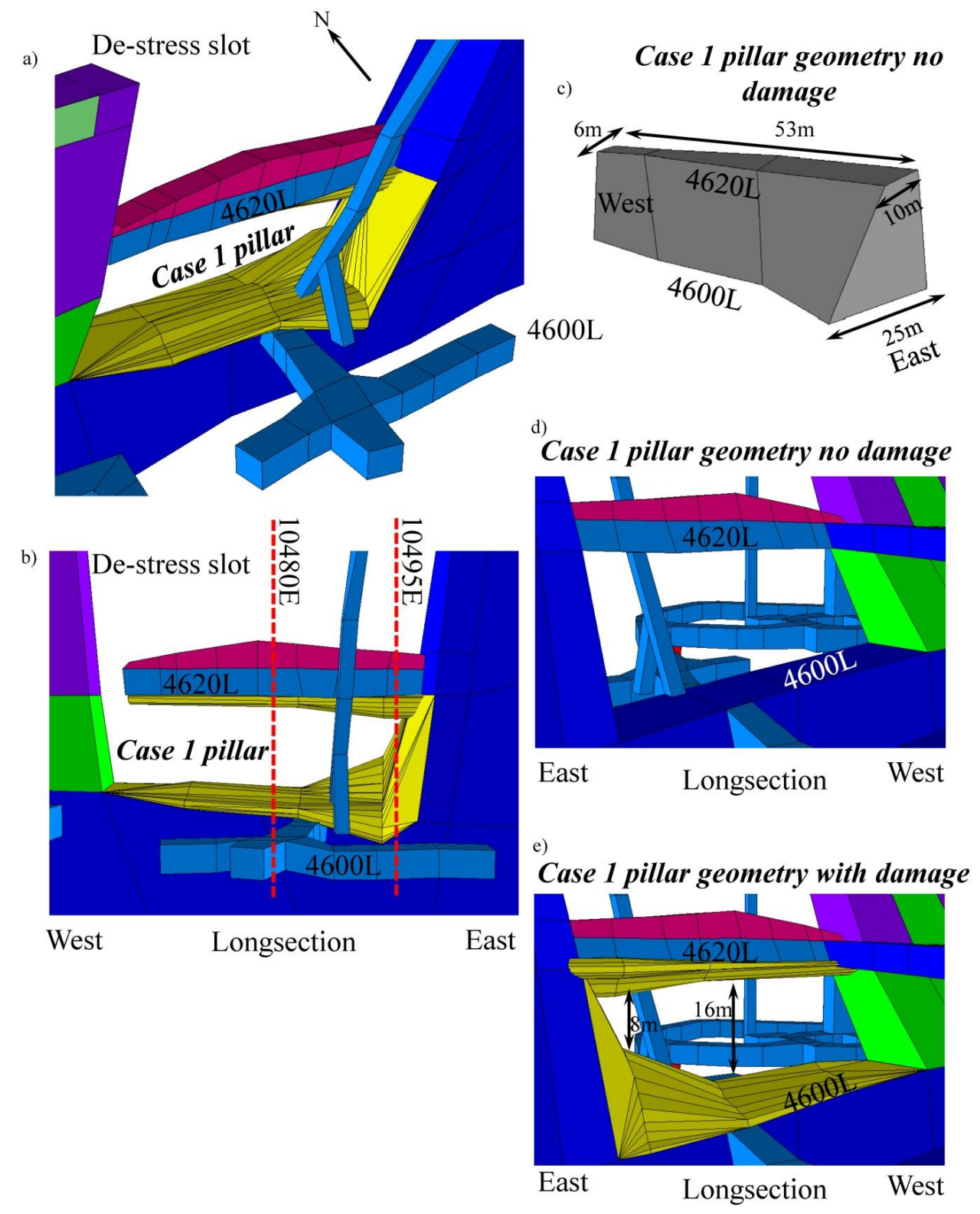

Figure 3 Golden Giant pillar (Case 1) geometry and sections $10480 \mathrm{E}$ and $10495 \mathrm{E}$ used for assessment. Mining shown to 2003. Yellow excavation block around the Case 1 pillar is the interpreted excavation damage zone

The pillar, based on microseismicity, fails without the occurrence of any large magnitude seismic events, i.e. events are of $M n<0$. Failure is driven by mining causing progressive loading and straining of the pillar (Coulson 2009).

In this section, first the failure process based on microseismic data and principal component analysis (PCA) data (plotted on lower hemisphere stereographic projections and graphically in cross sectional view) are presented. Next, an assessment of the change in PCA plane ellipsoid ratio and the principal stress-path in the pillar are presented. Finally, a summary and interpretation of the rupture zone creation process is provided.

PCA is a statistical method that is used to determine three dimensional linear trends along the principal axes of a coordinate system from a defined cloud of scattered data points (e.g. microseismicity). The method uses least square regression to fit vectors along the principal coordinate axes. 


\subsubsection{Failure process}

Microseismic source locations and microseismic event density (Figure 4) show that seismicity initiates near the eastern end of the pillar at the start of 2002 and progresses progressively westerly across the pillar to the start of 2003. The point of initiation is where the pillar has the smallest width to height ratio when excavation damage is considered.

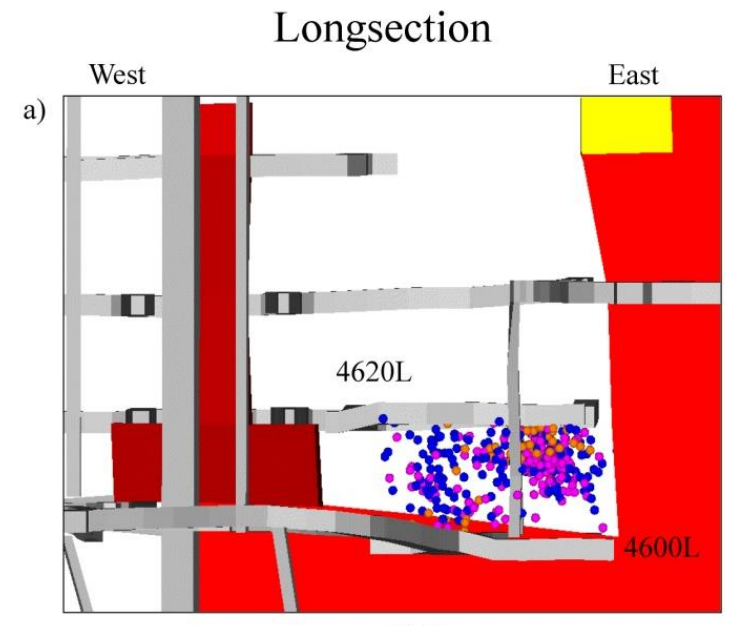

2002

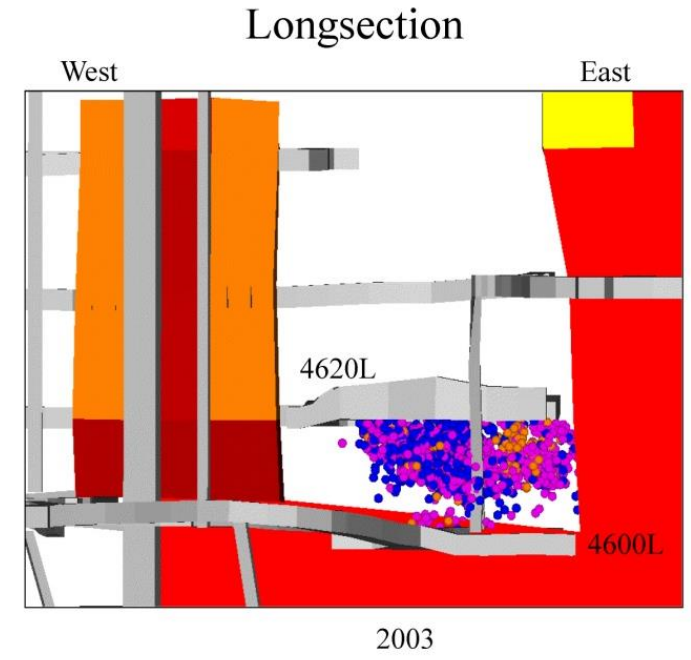

2003 c)

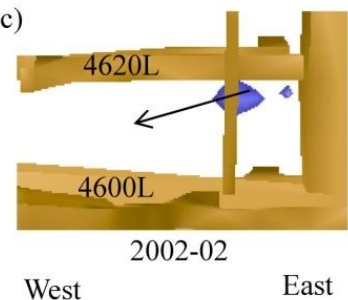

Longsection

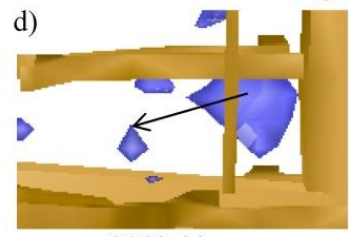

2002-08

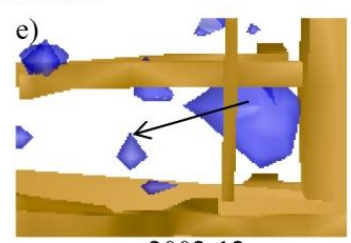

2002-12

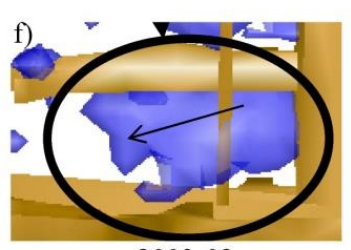

2003-02

Figure 4 Rupture zone initiation and propagation. (a-b) microseismic source locations for 2002 and 2003, respectively; (c-f) contour of microseismic density (five events per $125 \mathrm{~m}^{3}$ ) showing progression of rupture plane east to west from 2002-02 to 2003-03 (modified from Coulson, 2009)

This progression is associated with a rapid increase in microseismic event rates (Figure 5(a)). Graphical plots of the PCA derived planes are suggestive of the creation of a rupture zone where:

- Between dates 2002-04 and 2003-01: there is random fracturing in the pillar both visually (Figure 5(c)) and as indicated by lack of clear trend in the poles of the PCA planes plotted on a stereonet (Figure $5(\mathrm{~g})$ ) (concentration of poles, 10-12\%).

- Between dates 2003-01 and 2003-03: the PCA poles concentrate to a defined orientation of $52^{\circ} / 168^{\circ}$ (dip/dip direction) but are still dispersed (Figure $5(\mathrm{~h})$ ) (concentration of poles, $27-30 \%$ ). The PCA planes visually define a zone with a thickness, length, and general orientation (Figure 5(d)). The PCA planes did not correspond to any pre-existing discontinuities suggesting the creation of new fractures through intact rock.

- Between dates 2003-03 and 2003-04: there is further concentration of PCA plane poles to a defined mean orientation of $47^{\circ} / 161^{\circ}$ (dip/dip direction) (Figure 5(i)) (concentration of poles, 49-55\%). Visually the PCA plane data shows two pairs of conjugate en échelon arrays of fractures developing (some more evident than others) (Figures 5(f) and 6(a)).

- Between dates 2003-04 and 2003-12: some fractures in the pairs of the en échelon arrays have changed orientation to be in the direction of the array dip lines (Figures $5(f)$ and $6(b)$ ). This is also 
evident in the PCA plane poles plotted on the stereonet where there is still a mean fracture orientation of $56^{\circ} / 164^{\circ}$ (dip/dip direction) but a girdle line of poles has developed indicating a change in orientation of some fractures with a mean orientation of $77^{\circ} / 344^{\circ}$ (dip/dip direction) (Figure $5(\mathrm{j}))$. The change in fracture orientation to be aligned with the dip line of the rupture zone is suggestive of shearing and breakage through the initially created en échelon array of fractures (Figure 6(b)).
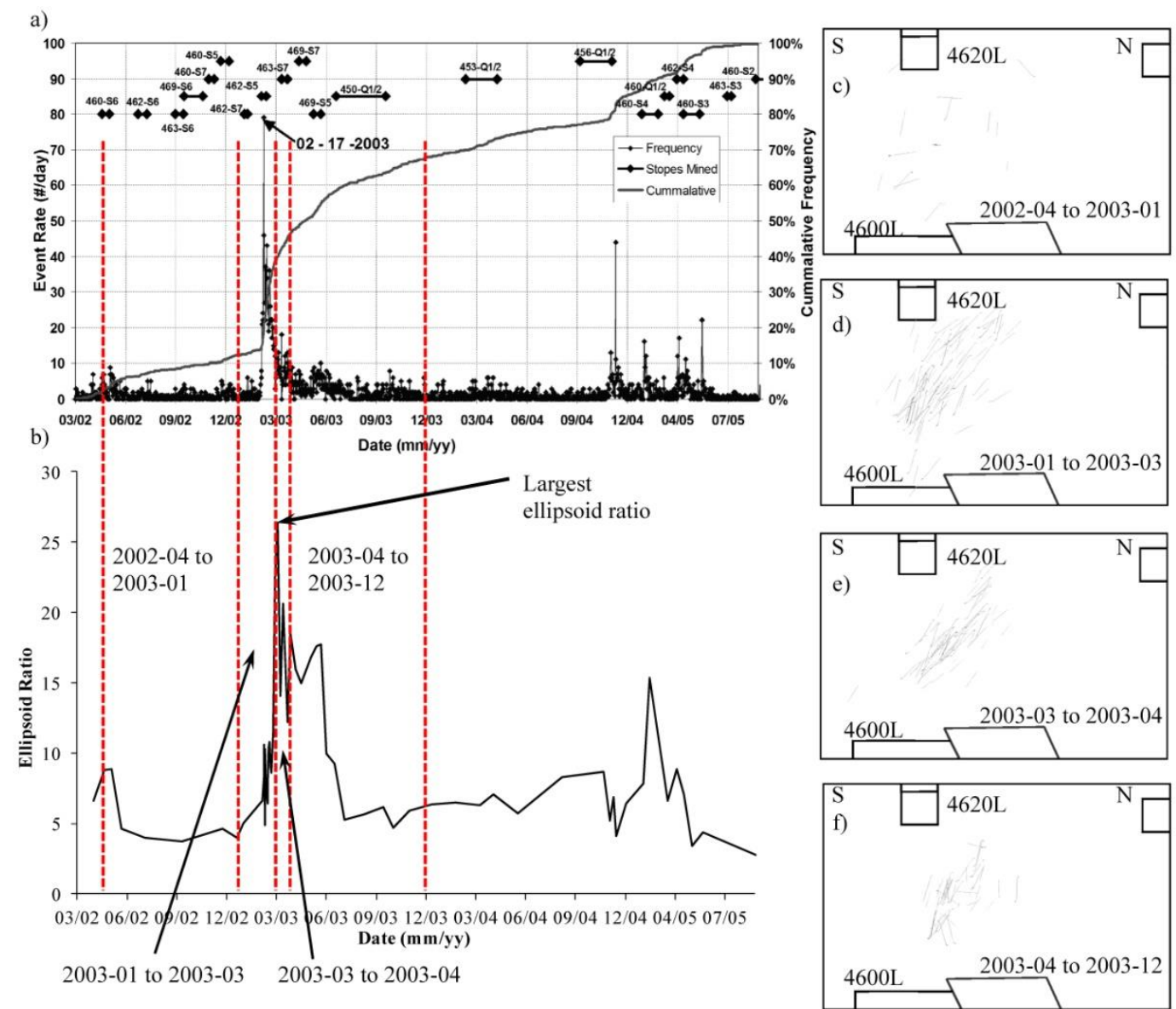

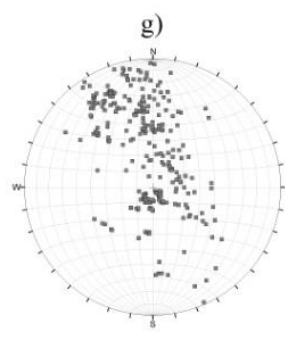

2002-04 to 2003-01, Random fracturing

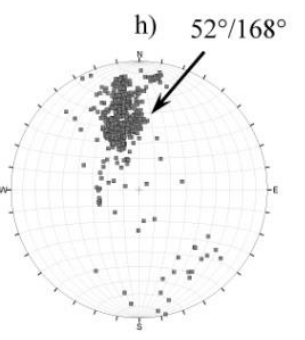

2003-01 to 2003-03, Fracture interaction

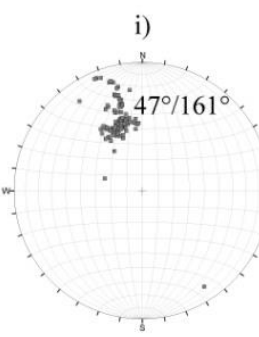

2003-03 to 2003-04, Fracture localization (fault formation)

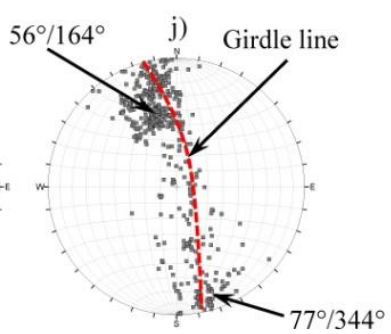

2003-04 to 2003-12,

Fracturing and shearing along localized faults

Figure 5 Microseismic event rates and PCA plane data, Case 1 pillar; (a) microseismic events rates and cumulative event count over time; (b) PCA ellipsoid ratio over time; (c-f) cross section (10480 E) through PCA planes showing the development of a fracture system over time; ( $g$-j) stereonets of PCA plane poles (dip/dip direction); (c-f) and ( $g-j$ ) ( $a$ and $c-f$ modified from Coulson 2009; $b$ and $g-j$ data provided by AL Coulson (pers. comm., 2010) 


\subsubsection{PCA ellipsoid geometry}

The change in PCA plane ellipsoid geometry over time is shown in Figure 5(b). Ellipsoid geometry is the ratio of the length of the PCA plane along dip to the length as measured along strike. This ratio has been used to identify pre-peak and post-peak strength states for rock undergoing deformation (Trifu \& Urbancic 1996; Coulson 2009). The pre-peak to post-peak transition occurs when there is a rapid increase in ellipsoid ratio. The ratio is relatively constant at a value of 5 until approximately March 2003 (Figure 5(b)) at which time the ratio rapidly increases to approximately 25 followed by a progressive more gradual decay back to a constant value of 5 around July 2003.
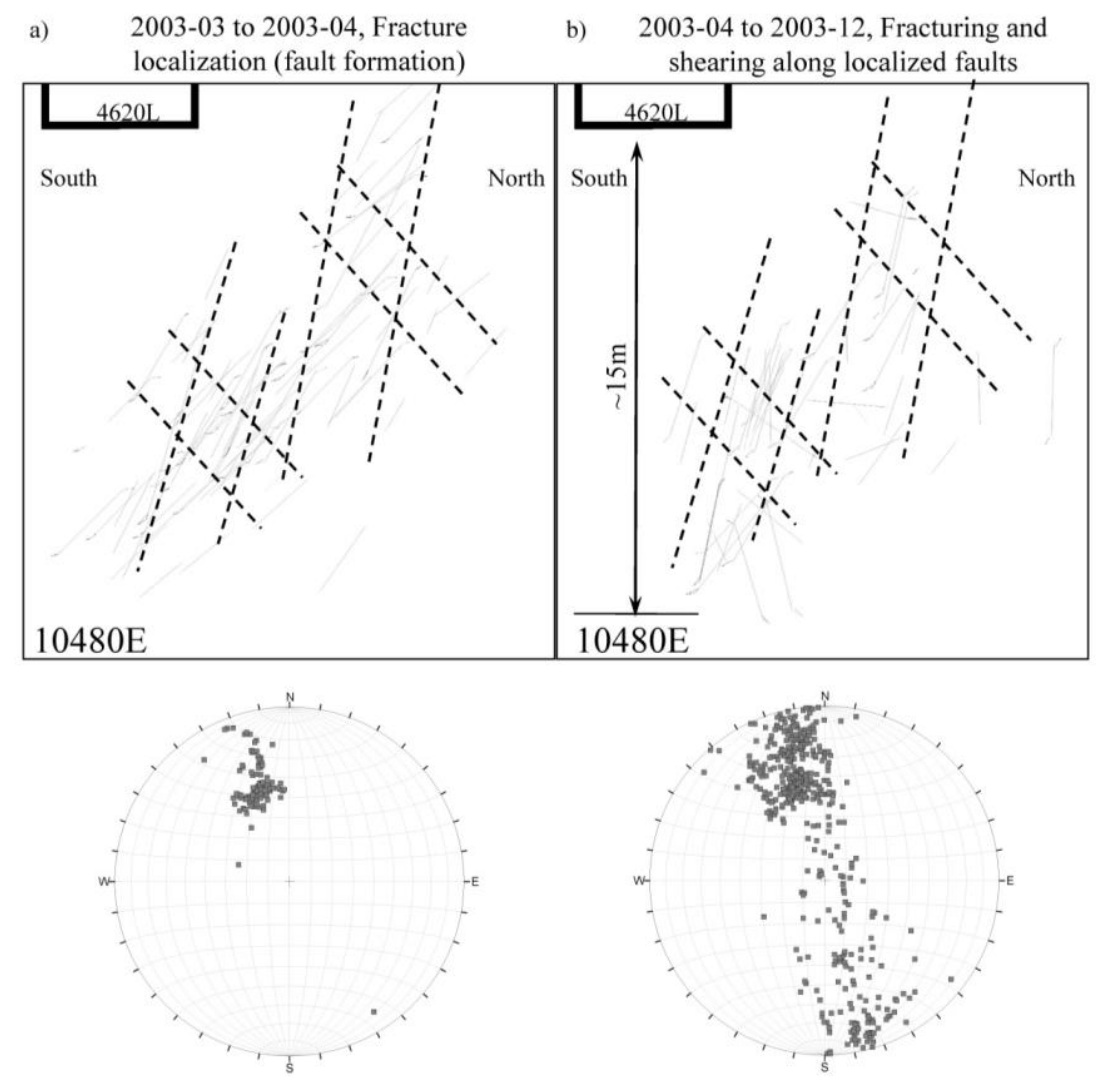

Figure 6 PCA plane cross-section 10480 E close up view showing. (a) development of two pairs of conjugate en échelon arrays; and (b) change in orientation of PCA poles in the direction of array dip line for date ranges 2003-03 to 2003-04 and 2003-04 to 2003-12, respectively. The fracture orientation change evident in (b) is suggestive of shearing along the rupture zone and breakage through the initially created en échelon array of fractures (a-b modified from Coulson 2009; data in stereonets provided by AL Coulson (pers. comm., 2010)

\subsubsection{Stress-path}

The stress-path in the Golden Giant pillar was assessed using the three-dimensional elastic boundary element code MAP3D v58 (Wiles 2011). Coulson (2009) previously used MAP3D for stress analysis of mining sequences at the Golden Giant Mine. The mine model built by Coulson (2009) was updated to include excavation damage around the Case 1 pillar resulting from induced stresses. The stress analysis was carried out in yearly mining steps, i.e. no mining, 2000, 2001, 2002, 2003.

Two sections along the pillar were analysed:

1. Near the initiation point of microseismicity at the eastern end of the pillar (10495 E) (Figure 3(b)).

2. Near the midpoint of the pillar (10480 E) (Figure 3(b)). 
These two sections are of interest because the modelling completed is elastic and the state-of-stress in the centre of the pillar will not be characteristic of the state-of-stress initiating the failure process at the eastern end. The stress-path in the centre of the pillar along section $10480 \mathrm{E}$ is not anticipated to near the potential rock mass strength envelope.

Stress-paths for each section are plotted in principal stress space in Figure 7 for the average stress magnitudes across the core of the pillar. Both stress-paths are above the bi-linear failure envelope cut-off, to the right of the spalling limits, and highly confined $\left(\sigma_{3}>30 \mathrm{MPa}\right)$. When excavation damage is taken into account, the stress-path representative of the eastern end of the pillar (10495 E), where the failure process initiates, is above the potential rock mass strength envelope while the stress-path in the pillar core is below the envelope.

The stress-path at initiation (section $10495 \mathrm{E}$ ) indicates that failure should occur due to shear rupture. As the initiated shear rupture propagates across the pillar, as indicated by the microseismic source locations (Section 2.1.1), stresses will be locally increased ahead of the propagating rupture tip creating the conditions for rock mass failure to occur, i.e. the pillar failure is due to rupture zone propagation across the pillar not due to the pillar stress representative of section $10480 \mathrm{E}$ being near or at the strength of the rock mass.

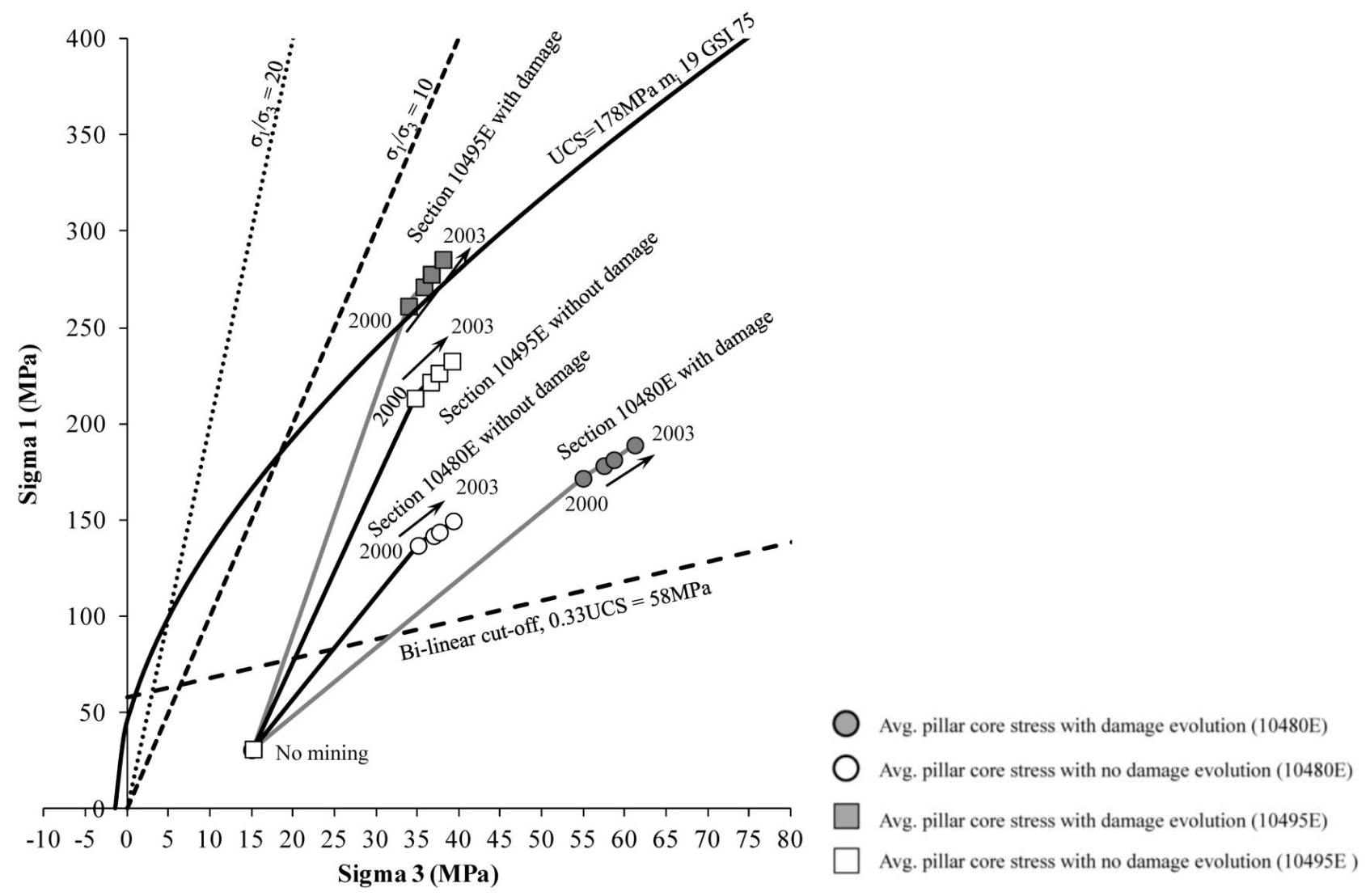

Figure 7 Case 1 average pillar stress-paths for sections $10495 \mathrm{E}$ and $10480 \mathrm{E}$ considering excavations without and with stress induced damage

\subsubsection{Summary and interpretation}

Fracturing processes leading to shear rupture zone creation in brittle rock and brittle analogue materials deformed in the laboratory under constant stress conditions, e.g. triaxial compression with constant lateral confinement and direct shear with constant normal stress, have been shown to initiate at peak strength (Lajtai 1969; Morgenstern \& Tchalenko 1967; Lockner et al. 1991); which is near coincident with maximum acoustic emission event rates (Scholz 1968); with rupture propagation and creation occurring in the postpeak region of the load-displacement curve (Lajtai 1969; Morgenstern \& Tchalenko 1967; Lockner et al. 
1991). Peak strength also has been identified using PCA ellipsoid geometry (Trifu \& Urbancic 1996; Coulson 2009) where the pre-peak to post-peak transition occurs when there is a rapid increase in PCA ellipsoid ratio.

Shear rupture zone creation in direct shear under constant normal stress boundary conditions is also consistent with the above summarised where peak strength occurs at peak fracture rates with rupture zone creation occurring post-peak strength. The created rupture zone geometries are dependent on the applied normal stress magnitude with the shear stress versus horizontal displacement response transitioning from completely brittle to ductile at low and high normal or confining stress magnitudes, respectively.

The fracturing process leading to rupture creation in the Case 1 pillar is described as follows:

- Initially, April 2002 to January 2003, random fracturing occurs in the pillar. Consistent with the stress state in the pillar being above the bi-linear cut-off (based on the stress-path) with relatively constant microseismic event rates and PCA ellipsoid geometry.

- A dense trend of fractures visually appears between January 2003 to March 2003.

- Around February 2003, peak microseismic event rates, a rapid increase in ellipsoid ratio, and a fracture zone that can be visually defined from the PCA data occurs suggesting peak strength is reached.

- From February 2003 to December 2003, conjugate pairs of en échelon fracture arrays form, microseismic event rates decay and PCA ellipsoid ratio deceases to a relatively constant low value suggesting the peak to post-peak transition of the pillar.

The fracturing process leading to shear rupture zone creation in the Case 1 pillar is consistent with the boundary conditions being constant stress: peak strength occurs at the point of maximum microseismic event rates concurrent with the rapid increase in PCA ellipsoid ratio with the shear rupture zone being created as the microseismic event rates decay and PCA ellipsoid ratios reduce, i.e. post-peak strength.

\subsection{Case 2 pillar - Williams Mine}

The Williams sill pillar is in the vicinity of active mining. The pillar, based on microseismicity, fails with the occurrence of a number of magnitude seismic events $(M n \geq 0)$ and a rockburst $(M n=2.7)$ as a result of mining causing progressive loading and straining of the rock. This section specifically focuses on the data located in a region between eastings $9400 \mathrm{E}$ and $9450 \mathrm{E}$ (from stope 26 to 23) and levels 9390L and 9415L (Figure 8).

A cross-section through $9437 \mathrm{E}$ (middle of stope 24) (Figure 8) is used as the primary section of analysis to investigate the failure processes and behaviour along the sill's strike. The analysis of a limited section is applicable due to the geometry of the sill pillar and the relatively linear advance of mining from east to west. As mining progresses, a stress front ahead of the mining advance is generated, this front of high stress is systematically progressed across the sill pillar and thus every section of ground in the sill is subjected to a similar stress-path during mining progression and to similar behaviour due to similar rock mass characteristics across the sill pillar volume.

First the failure process based on microseismic data and PCA data (plotted on stereographic projections) is presented. Next, a detailed assessment of the change in PCA plane ellipsoid ratio is completed. This is followed by assessment of extensometers and the principal stress-path in the pillar. Finally, a summary and interpretation of rupture zone creation is provided.

\subsubsection{Failure process}

Microseismic source locations suggest the progressive development of a fracture plane in the centre of the pillar (Figure 9(c-g)) with a distinct localisation in 06/2003 (Figure 9(g)). There are a series of increases in event rates (\#/week) creating a stepped cumulative frequency curve with the highest event rate occurring prior to a rapid decline in seismic events (Figure 9(a)). The largest event rate increases on June 2001, May 
2003, September 2003 are coincident with larger seismic events or rockbursts, $M n=3.1, M n=2.7$, and $M n=3.5$, respectively, that are located within or near the Case 2 pillar region of interest (Coulson 2009).

Unlike the Case 1 pillar fracture process shown in Figure 5(c-f), there are an insufficient number of PCA planes in Case 2 to show the fracturing process leading to rupture zone creation. Although, the understanding from the observations between the PCA plane plots and poles plotted on stereonets can be used to gain additional understanding, i.e. the girdle line in the stereonets from Case 1 appears to be related to fracture orientation change suggesting shearing along a rupture zone (Figure 5). The poles plotted on stereonets yearly from 1999 to 2004 are shown on Figure 10. Unlike the Case 1 pillar where the poles tended to become increasingly concentrated to a more defined orientation up to the interpreted peak strength followed by a girdle line developing, for this case, the poles start relatively concentrated in 1999-2000 (Figure 10(a), pole concentration 40-45\%, 38 $/ 181^{\circ}$, dip/dip direction) and then progressively show a scattering in 2001 (Figure 10(b), pole concentration $18-20 \%, 47^{\circ} / 166^{\circ}$, dip/dip direction) but with evident orientation clustering. This behaviour progresses and in 2003 a non-concentrated or disbursed girdle line emerges (Figure 10(d)) with a more defined girdle line in 2004 (Figure 10(e)). From the Golden Giant, Case 1, data (Section 2.1.1), the girdle line is potentially related to fracture orientation changes along the rupture zone being created suggesting shearing along a created rupture zone. 
a)

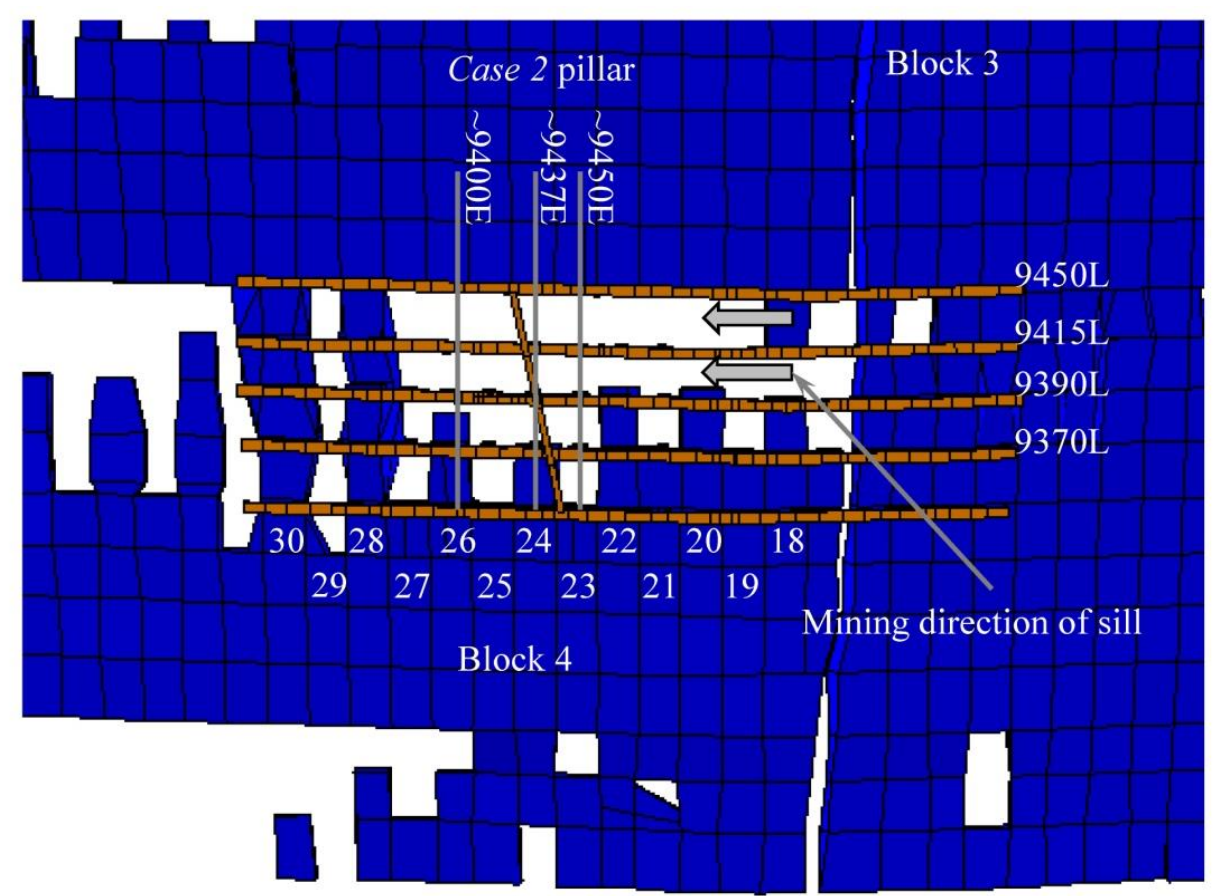

b)

Cross section 9437E looking west. Pillar geometry development over time

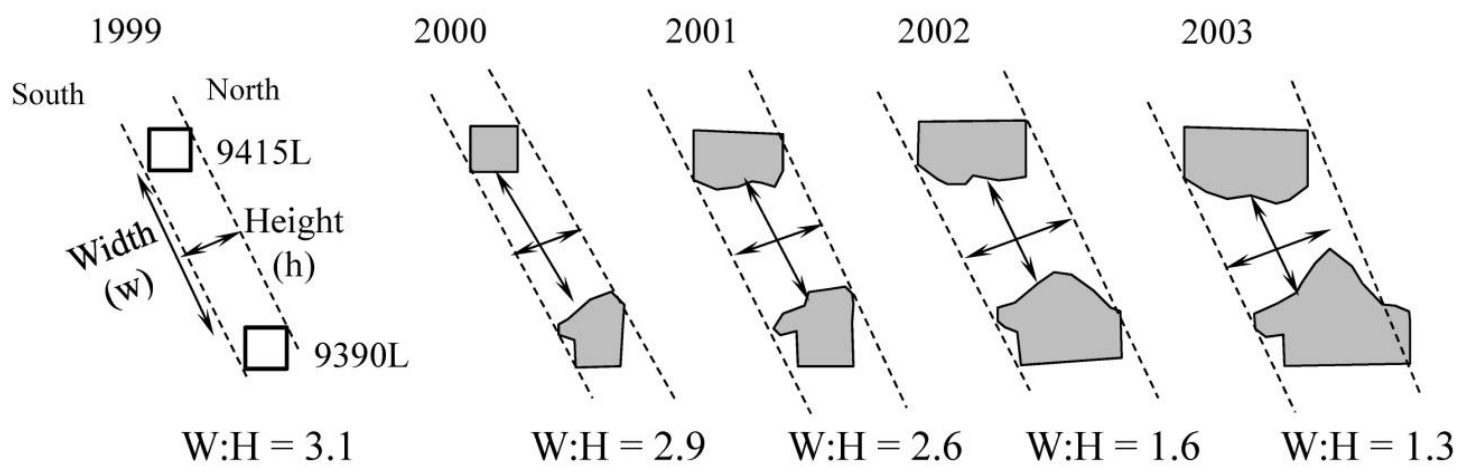

Figure 8 Williams sill pillar (Case 2); (a) geometry and section used for assessment (9437 E); (b) schematic change in pillar geometry over time along $9437 \mathrm{E}$ (grey areas indicate interpreted excavation damage zone evolution over time) 
a) —EventRate $\diamond$ Large Events $\bullet-$ Stopes Mined $\quad$----. Cumulative Frequency

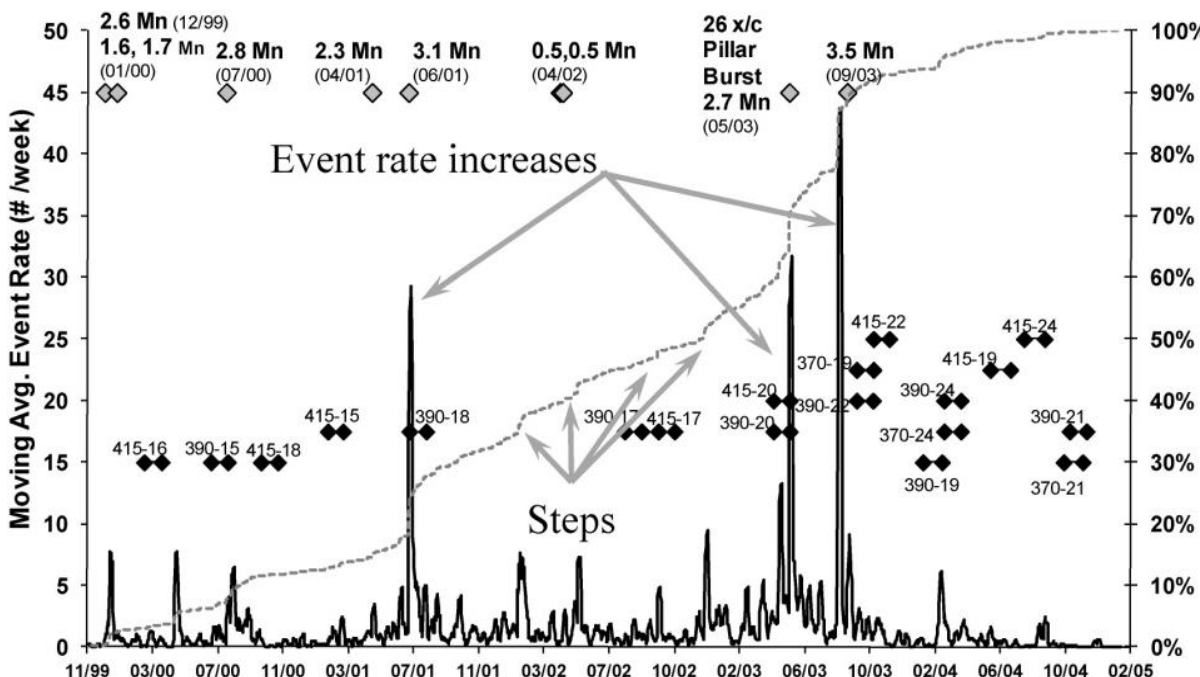

Date $(\mathrm{mm} / \mathrm{yy})$

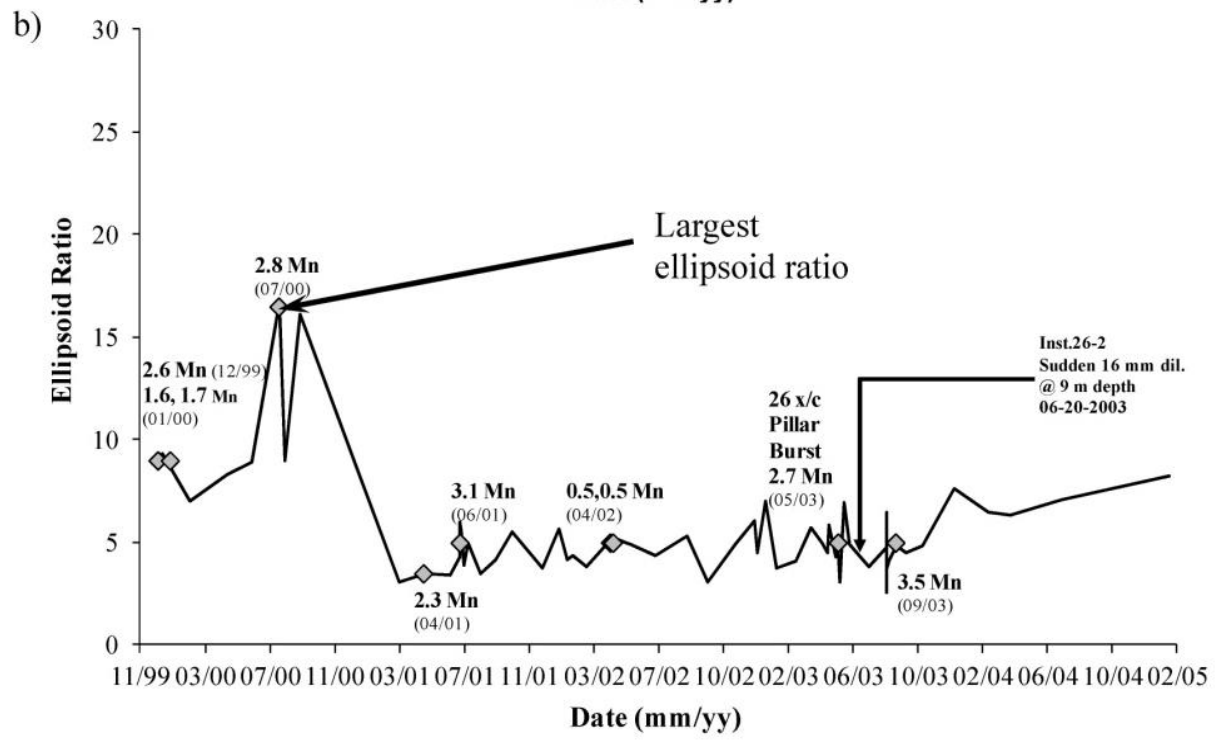

c)

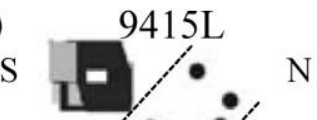

S

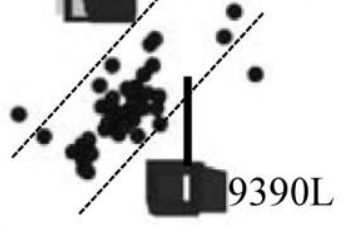

$12 / 26 / 1999$

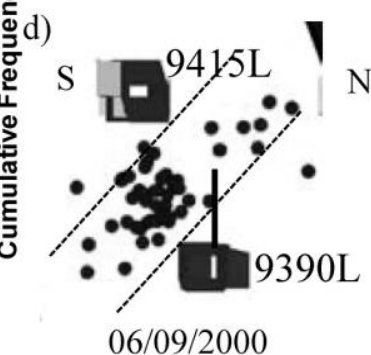

e)

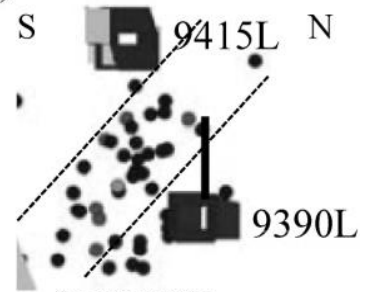

$06 / 29 / 2001$

f)

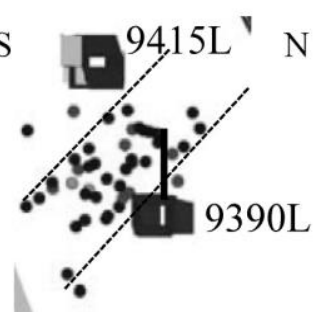

$06 / 26 / 2002$

g)

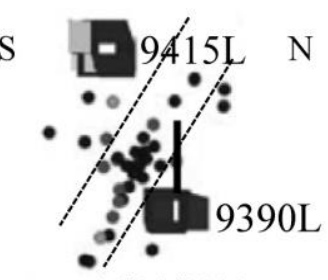

$06 / 20 / 2003$

Figure 9 Compilation of microseismic event rates and source locations for the Case 2 pillar; (a) microseismic events rates and cumulative event count over time; (b) PCA ellipsoid ratio

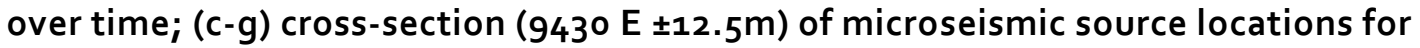
dates indicated. (a-b re-plotted using data provided by AL Coulson (pers. comm., 2010); (c-g) modified from Coulson 2009) 

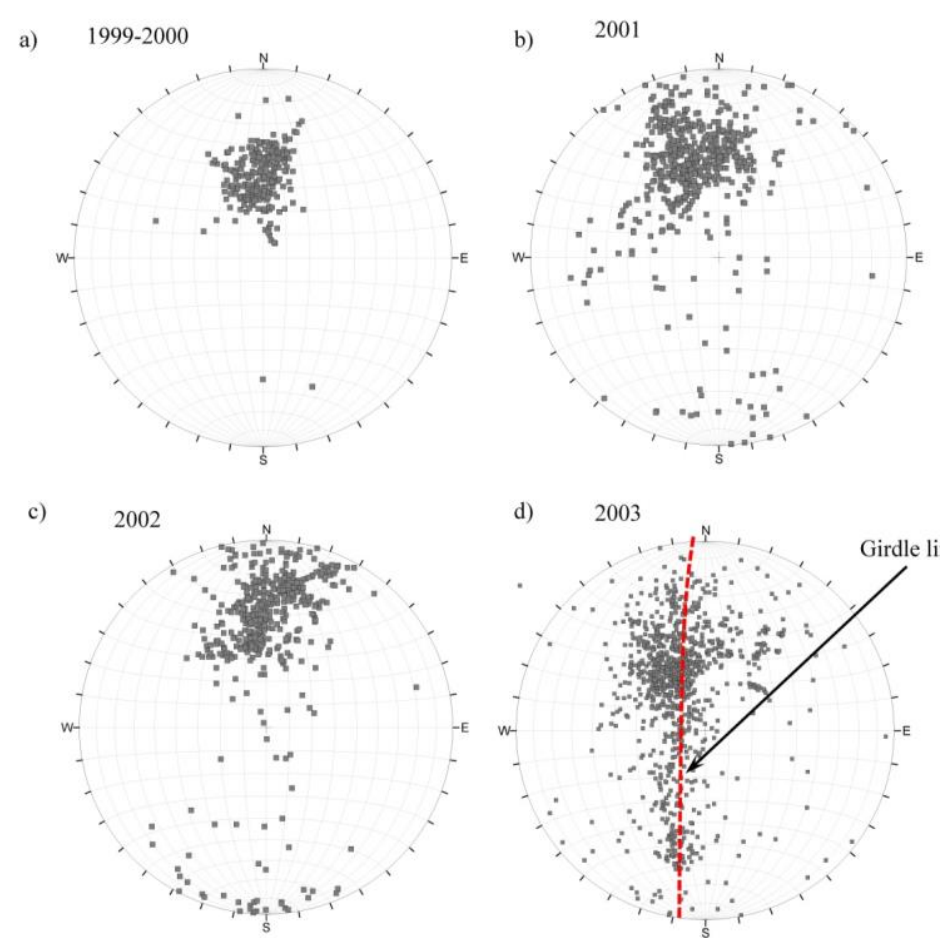

d) 2003

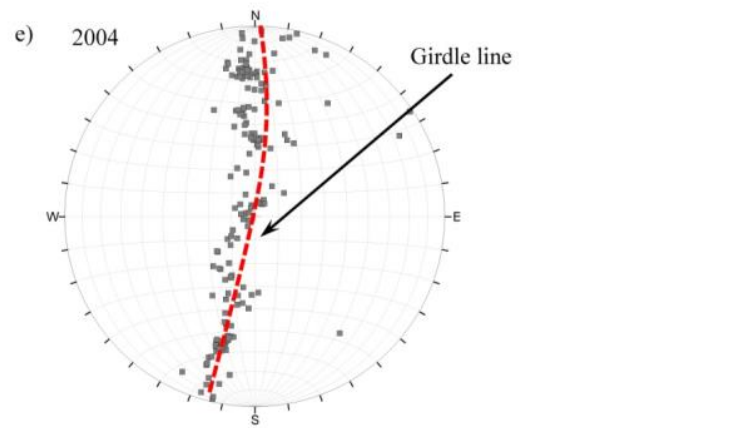

Figure 10 (a-e) Stereonets of PCA plane poles (dip/dip direction) for years indicated. Poles are relatively concentrated in (a) and disburse over time eventually forming a girdle line in 2004 (e) (data provided by AL Coulson (pers. comm., 2010))

\subsubsection{PCA ellipsoid geometry}

PCA ellipsoid ratio, Figure 9 (b), is relatively constant at a value of 8 between September 1999 and June 2000. The ratio increases to 16 just prior to $07 / 2000$ followed by a progressive more gradual decay back to a constant value of 5 around 03/2001.

\subsubsection{Extensometer response}

SMART-cables (Hyett et al. 1997), which are multi-point borehole extensometer type instruments, are located in the volume of interest. Deformations relative to the toe of the cables are shown on Figure 11 which also has a plan view of the $9390 \mathrm{~L}$ indicating the locations of the five cables in the back of the access drift (four at crosscut intersections).

Overall, there is little response along the cables to the end of 2000 suggestive of near elastic excavation response. This is followed by near boundary displacements suggestive of up to $6 \%$ bulking (as a result of stress induced slabbing/spalling) near the excavations generally mid to end of 2002. Between June or December 2002 and June 2003, the bulking zone suddenly deepens to between 4 and $10 \mathrm{~m}$. This behaviour change is clearly related to deep seated rock mass failure and is suspected to be the result of a fracture/rupture zone developing in the core of the pillar which in turn interacts with the excavation 
damage zone (previously spalled/slabbed rock). Bulking at depth imposes deformations on this stress damaged rock mass which then compresses the fractured rock (Cable 2 or 4, Figure 11) or stops bulking (Cable 1, Figure 11). Due to the fact that there is no evidence of a gradual propagation of the depth of failure or bulking, it is reasonable to assume that the bulking at depth (after June or December 2002) is directly related to the creation of a shear rupture zone in the pillar core. This fracture zone then interacts with the excavation damage zone to cause the observed extensometer records. This process of rupture zone interaction with the excavation damage zone influencing the extensometer measurements is illustrated schematically in Figure 12.
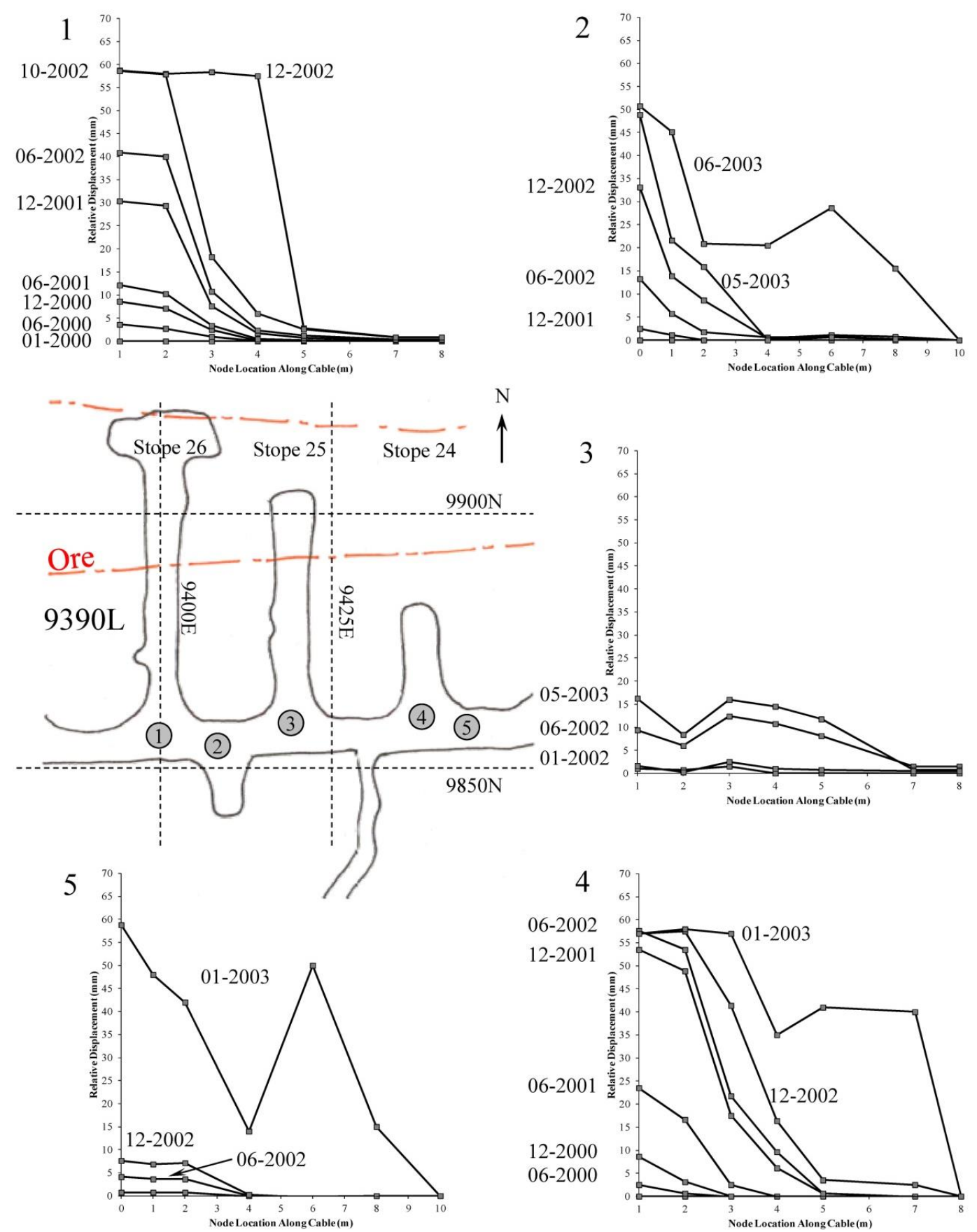

Figure 11 SMART-cable responses ( 1 to 5 ) relative to the toe of the cable. Cables 1-5 are shown on the level plan for $9390 \mathrm{~L}$ (stope numbers, northings and eastings labelled) (data provided by AL Coulson (pers. comm., 2010)) 


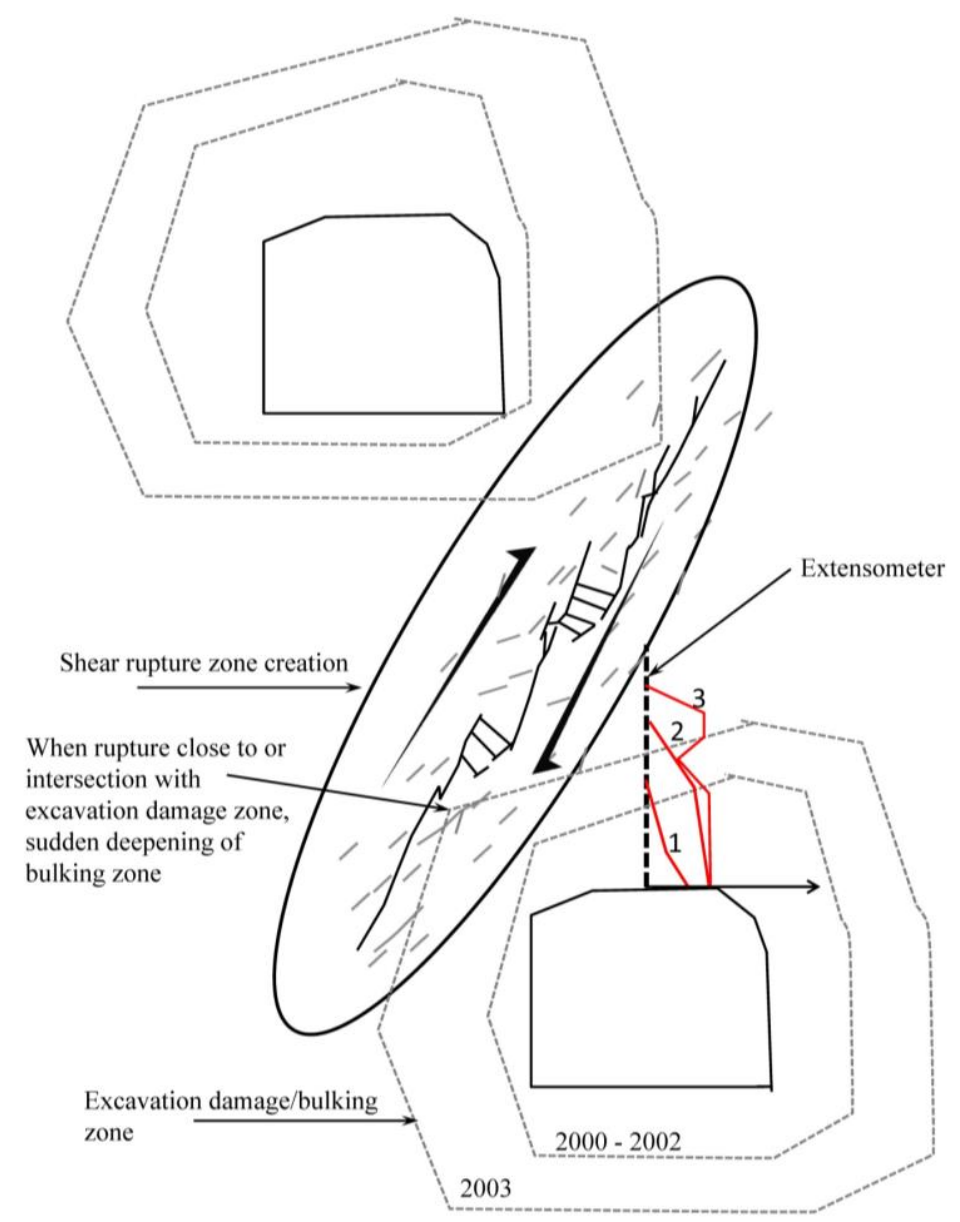

Figure 12 Schematic of pillar core rupture interacting with damage zone (increasing in depth over time) and extensometer response. Numbers 1-3 for extensometer curves; (1) near excavation spalling/bulking (excavation damage envelope 2000-2002); (2) excavation damage zone interacts with rupture zone (2003); and (3) intersection of excavation damage zone with rupture leading to compression of previously spalled rock

\subsubsection{Stress-path}

The stress-path in the Williams pillar was also assessed using MAP3D v58 (Wiles 2011). The mine model built by Coulson (2009) was updated to include: (1) the observed excavation damage around the Case 2 pillar resulting from induced stresses; and (2) the footwall crosscut drifts which were used to access the ore. The stress analysis was carried out in yearly mining steps, i.e. no mining, 2000, 2001, 2002, 2003, 2004.

The average pillar stress-paths without and with excavation damage evolution for section $9437 \mathrm{E}$ through the pillar in principal stress space are shown in Figure 13. When excavation damage is not taken into account, the stress-path is compressive well beyond 2003, above the bi-linear cut-off, and well below the potential strength envelope for the rock mass.

When excavation damage is considered, the stress-path shows an increase in the major $\left(\sigma_{1}\right)$ and minor $\left(\sigma_{3}\right)$ principal stress to 2001 and then progresses to lower and lower magnitudes of minor principal stress at a more or less constant major principal stress. The stress-path crosses the spalling limit $\left(\sigma_{1} / \sigma_{3}=10\right)$ in 2002 and the potential rock mass strength (plus spalling limit $\sigma_{1} / \sigma_{3}=20$ ) in 2003. Extensional fracturing would therefore be expected in or just before 2002. The calculated stress-path becomes tensile (negative values of $\sigma_{3}$ ) in 2004. This tensile stress point is an artifact of the elastic continuum model that allows tension. In reality, tension is capped by the rock mass tensile strength which is much less than the modelled tension. 


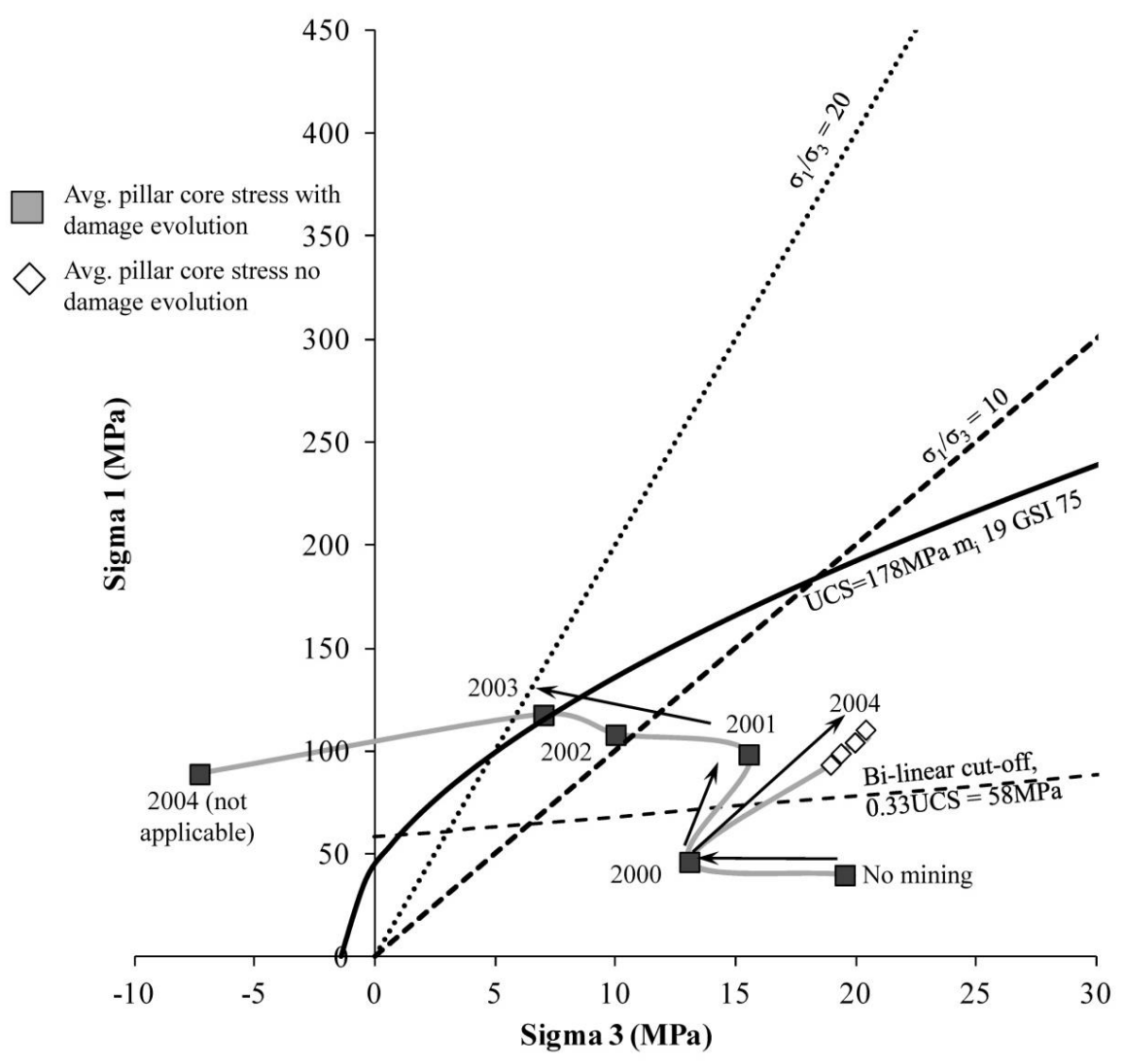

Figure 13 Case 2 average pillar stress-paths for section $9437 \mathrm{E}$

The stress-path that was determined from the model which considered excavation damage evolution clearly illustrates the failure sequence supported by seismic clustering in combination with extensometer responses (rock mass bulking). Up to the end of 2001, the pillar core is stable with a safety margin when compared to the anticipated rock mass strength. In 2002, the stress state gets close to or exceeds the spalling limit (at $\sigma_{1} / \sigma_{3}=10$ ). Thus, the damage mechanism in the pillar core changes from confined shear (which is not reached because the major principal stress is not high enough) to processes with extensional failure.

In 2003, the stress-path reaches the failure envelope for shear failure and the combined effect of extensional damage above the initiation threshold and shear failure leads to sudden rupture zone creation with related rock mass straining. This in turn causes a deepening of the excavation damage zone and thus deep seated bulking as reflected in the extensometer readings described in the previous section.

\subsubsection{Summary and interpretation}

Four different interpretation scenarios were explored in an effort to understand the pillar failure process for Case 2:

1. Failure under constant stress boundary condition.

2. Failure under constant stiffness boundary condition.

3. Failure due to changing effective pillar geometry resulting in the pillar core stress exceeding the rock mass strength.

4. Failure due to a combination of a stiffness boundary condition and a changing pillar geometry resulting in a change in pillar core stress and pillar boundary condition to one of stress control.

Due to space limitations only interpretation one and four are discussed. 
Figure 14 summarises the analyses and results for the Case 2 pillar and shows when the following occur: magnitude seismic events, microseismic event rates, peak ellipsoid ratio, peak strength as interpreted by Coulson (2009), crossing of the fracture initiation threshold, near excavation and deep seated deformations as determined from the extensometers, crossing of the spalling limits, crossing of the empirical pillar stability lines (not presented in this paper), and crossing of the estimated Hoek-Brown rock mass strength envelope.

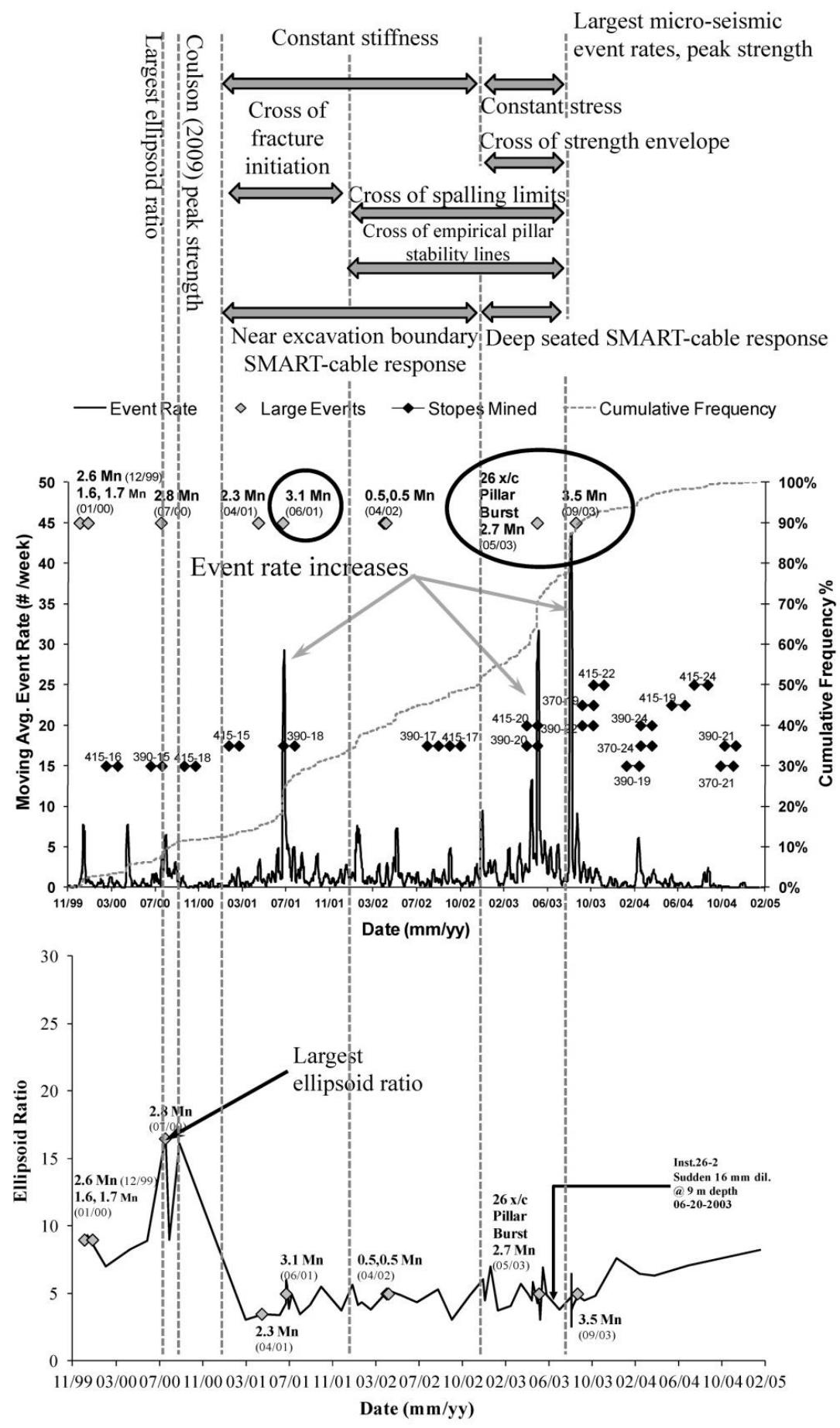

Figure 14 Compilation of Case 2 analyses; for explanation see text. Circled seismic events are in the region of interest for the Case 2 pillar 


\subsubsection{Interpretation 1-constant stress boundary conditions}

Assuming that the Case 2 pillar fails under a constant stress boundary condition, as assumed by Coulson (2009), peak strength occurs at the point of highest ellipsoid ratio between July and November of 2000 and the shear rupture zone in the pillar is created post-peak strength (Figure 14). While a possible interpretation, this interpretation is not consistent with when the stress-path crosses the potential strength envelope in principal stress space, the occurrence of maximum microseismic event rate, or the crossing of various empirical pillar stability lines. All of these occur after the occurrence of the peak ellipsoid ratio. Therefore, the pillar likely did not fail under a constant stress boundary condition.

\subsubsection{Interpretation 4-combination}

An alternate interpretation embraces elements of all three potential contributing factors, i.e. links the previous three interpretations. This fourth interpretation assumes that the initial boundary conditions surrounding the Case 2 pillar are of a stiffness condition and the peak ellipsoid ratio speculatively indicates when the internal peak strength envelope of the pillar is reached which cannot be tracked with the 3D elastic numerical stress modelling tool. As mining continues around the pillar, damage zones around the excavations surrounding the pillar develop. Initially, these damage zones increase the major principal stress and normal stiffness along the rupture zone being created in the pillar core. During this time, pre-peak fracture systems are created in the pillar core and result in early (pre-peak) generation of seismic events and the stepped nature of the microseismic event cumulative frequency curve. The damage zones continue to deepen around the excavations. This creates the ability for the pillar core fracture systems, creating a rupture zone, to interact with the excavation damage zones. This interaction is the potential cause of the $M n=2.7$ pillar wall strainburst in May of 2003. As the pillar core fracture systems dilate and interact with the excavation damage zones, they will have the effect of loading the damage zones to the point where, if the rock mass characteristics are ideal, a violent failure could occur and generate a seismic event/rockburst.

This interpretation is consistent with the SMART-cable monitoring data which shows dilation in the pillar core concurrent with the $M n=2.7$ pillar wall strainburst. At this point, the damage zones have now deepened sufficiently to generate low confining stress conditions in the pillar. This allows for longer tensile fractures to propagate and the pillar boundary condition to change from one of stiffness to one of constant stress, as also supported by the decreasing normal stiffness along the rupture zone from the start of 2002 to the end of 2003, not presented in this paper, leading to pillar rupture and a large energy release as the pillar fails undergoing a stress drop to a residual strength state.

This interpretation is most consistent with all records of rock mass behaviour, monitoring data, and analyses completed.

\section{Conclusions}

Two pillar case histories were analysed and re-interpreted. It was found that the Golden Giant pillar (Case 1) failed by the creation of a shear rupture zone which initiated at the east end of the pillar (at the location of the smallest $\mathrm{W} / \mathrm{H}$ ratio) and propagated westerly across it. The processed monitoring data in the form of microseismic event rates, PCA plane locations, PCA plane ellipsoid ratios, and stress-paths were consistent with shear rupture zone creation occurring under essentially constant stress boundary conditions.

While mine failure cases are commonly interpreted using the assumption of constant stress boundary conditions, previously not recognised and different assumptions were required to interpret the Williams Mine pillar (Case 2). The Case 2 pillar failed by the creation of a shear rupture zone, which progressively developed in the pillar core. The processed monitoring data in the form of microseismic event rates and source locations, PCA plane ellipsoid ratios, SMART-cables, and stress-paths were consistent with shear rupture zone creation occurring under an initial stiffness boundary condition which transitioned to a constant stress boundary condition as the pillar geometry changed due to stress induced rock mass damage around the excavations surrounding the pillar. 
Under constant stress boundary conditions, shear rupture zones are initiated at or just after peak strength and are created post-peak. Under constant stiffness boundary conditions, shear rupture zones are initiated pre-peak maximum strength. Practically, failure processes under constant stress have the potential to release energy rapidly as a rock volume progresses from peak to post-peak strength. In brittle rocks under limited straining this is likely only to generate a single event. Under constant stiffness, because rupture creation occurs pre-peak strength, there is a potential for multiple large energy release events during the failure process. If areas in a mine can be identified under the different boundary conditions, seismic hazard assessments and application of mitigation measures, such as enhanced ground support, could be improved.

\section{Acknowledgement}

The work summarised in this paper is from a chapter from Dr Bewick's PhD thesis. Dr Adam Coulson is thanked for providing the case history data and analyses he used and conducted for his PhD thesis.

\section{References}

Bewick, RP 2013, 'Shear rupture of massive brittle rock under constant normal stress and stiffness boundary conditions', PhD thesis, University of Toronto, Toronto.

Bewick, RP, Kaiser, PK, Bawden, WF \& Bahrani, N 2013a, 'DEM simulation of direct shear: 1. Rupture under constant normal stress boundary conditions', Rock Mechanics and Rock Engineering, DOI: 10.1007/s00603-013-0490-8.

Bewick, RP, Kaiser, PK, Bawden, WF 2013b, 'DEM simulation of direct shear: 2. Grain boundary and mineral grain strength component influence on shear rupture', Rock Mechanics and Rock Engineering, DOI: 10.1007/s00603-013-0494-4.

Bewick, RP, Kaiser, PK, Bawden, WF 2013c, 'Shear rupture under constant normal stiffness boundary conditions', Tectonophysics, DOI: 10.1016/j.tecto.2014.07.016.

Coulson, AL 2009, 'Investigation of the pre to post peak strength and behaviour of confined rock masses using mine induced microseismicity'. PhD thesis, University of Toronto, Toronto.

Hallbauer, DK, Wagner, H \& Cook, NGW 1973, 'Some observations concerning the microscopic and mechanical behaviour of quartzite in stiu triaxial compression tests', International Journal of Rock Mechanics and Mining Sciences \& Geomechanics Abstracts 10, pp. 713-726.

Hyett, AJ, Bawden, WF, Lausch, P, Moosavi, M, Ruest, M \& Pahkala, M 1997, 'The S.M.A.R.T. cable bolt: an instrument for the determination of tension in 7-wire strand cable bolts', in In E Broch, A Myrvang \& G Stjern (eds), Proceedings of the International Symposium on Rock Support - Applied Solutions for Underground Structure, Helli Grafisk, Oslo, pp. 25-40.

Lajtai, EZ 1969, 'Mechanics of second order faults and tension gashes', Geological Society of America Bulletin, vol. 80, no. 11, pp. 2253-2272.

Lockner, DA, Byerlee, JD, Kuksenko, V, Ponomarev, A \& Sidorin, A 1991, 'Quasi-static fault growth and shear fracture energy in granite', Nature, vol. 350, pp. 39-42.

Morgenstern, NR, Tchalenko, JS 1967, 'Microscopic structures in kaolin subjected to direct shear', Geotechnique, vol. 17, no. 4, pp. 309-328.

Scholz, CH 1968, 'Microfracturing and the inelastic deformation of rock in compression', Journal of Geophysical Research, vol. 73, no. 4, pp. 1417-1432.

Trifu, Cl \& Urbacic, TI 1996, 'Fracture coalescence as a mechanism for earthquakes: observations based on mining induced microseismicity', Tectonophysics, vol. 261, pp. 193-207.

Wiles, TD 2011, Map3D: Mine Analysis Package in Three Dimensions, version V58, Mine Modelling Pty Ltd, Mt.Eliza, http://www.map3d.com 